\title{
Morphological Spectrum of Lesions Seen in Thyroidectomy Specimens At A Tertiary Care Institute
}

\section{Iram Nadeem Rana ${ }^{1}$, Samra Sameen ${ }^{2}$, Sahar Iqbal $^{3}$, Tazeen Anis ${ }^{4}$}

\begin{abstract}
Objective: To determine the morphological spectrum of thyroid lesions encountered in thyroidectomy specimens at a tertiary care institute.

Methods: It was a retrospective study conducted in Pathology Department, Allama Iqbal Medical College, Lahore. A retrospective manual collection of data was done from record registers, for the years 2012 \& 2013.

Results: A total of 307 cases were retrieved with age range of 16-70 years. Amongst them, 47 were males and 260 were females. Non neoplastic conditions outnumbered the neoplastic lesions as 229(75\%) cases were of colloid goiter. Hashimoto thyroiditis was present in 12(3.9\%) specimens and associated hyperplastic changes were seen in $15(4.9 \%)$ cases. There were $19(6.2 \%)$ cases of papillary carcinoma, $3(0.9 \%)$ cases of follicular carcinoma, 3(0.9\%) cases of medullary carcinoma, $1(0.3 \%)$ case of insular carcinoma and $2(0.6 \%)$ anaplastic carcinoma. Papillary microcarcinoma was seen in 4(1.3\%) cases and medullary microcarcinoma in $1(0.3 \%)$ case. Follicular adenoma comprised $29(9.4 \%)$ cases and Hurthle cell adenoma $3(0.9 \%)$ cases. Study data also showed $1(0.3 \%)$ rare case of hyalinizing trabecular tumor.

Conclusion: Non neoplastic thyroid diseases are more common as compared to neoplastic lesions. Papillary carcinoma is most common thyroid malignancy encountered in our setting.

Key Words: Thyroidectomy, Colloid goiter, papillary carcinoma
\end{abstract}

\section{Introduction}

$\mathrm{T}$ he thyroid gland is responsible for secretion of two crucial hormones Thyroxine and Calcitonin. ${ }^{1}$ The incidence of thyroid diseases is rising due to increase in aging population and an increased use of cross sectional imaging of head, neck and chest. ${ }^{2}$ Effected patients may remain relatively asymptomatic, may present with symptoms of hyperfunction, hypofuction or a mass in front of the neck. Diffuse thyroid lesions involve the entire gland, such as hyperplasia and thyroiditis. Nodular lesions are those

\begin{tabular}{|c|c|c|}
\hline 1. & Iram Nadeem Rana & Samra Sameen \\
\hline 3. & Sahar Iqbal & Tazeen Anis \\
\hline 1,2 . & Pathology Department,, & vices Hospital, Lahore \\
\hline & Pathology Department, $A$ & ed Medical College, Lahore \\
\hline 4. & Pathology Department, & oal Medical College, Lahore \\
\hline \multicolumn{3}{|c|}{$\begin{array}{l}\text { Correspondence: } \\
\text { Dr. Samra Sameen } \\
\text { Assistant Professor, Department of Pathology, Services Institute of Medical } \\
\text { Sciences, Lahore } \\
\text { samra.sameen@gmail.com }\end{array}$} \\
\hline & Submission Date: & $18-08-2020$ \\
\hline & 1st Revision Date: & $19-09-2020$ \\
\hline & Acceptance Date: & $25-10-2020$ \\
\hline
\end{tabular}

disorders that produce a clinically palpable nodule which may be solitary or multiple. ${ }^{3}$ Around $10-15 \%$ of thyroid nodules turn out to be cancerous on investigations. So it is recommended that all nodules larger than $1-1.5 \mathrm{~cm}$ must be evaluated. For such patients early detection and treatment are associated with excellent prognosis. ${ }^{2}$ Thyroidectomy is mainstay of treatment in malignant thyroid diseases. For benign disorders, surgery resorted to for cosmetic or pressure symptoms.

\section{Objective}

To determine the morphological spectrum of thyroid disorders in thyroidectomy specimens recei-ved in department of Pathology of Allama Iqbal Medical College (AIMC), over a period of 2 years.

\section{Methods}

It is a retrospective study spanned over 2 years, conducted in Histopathology section of Department of Pathology, AIMC, Lahore. Demographic data was collected from Record Registers for the years 2012 \& 2013 for all the thyroidectomy specimens (either total 
thyroidectomy, partial thyroidectomy or lobectomy). A total of 307 samples of thyroid surgeries were received during this period. Slides were retrieved for verification of the morphological diagnosis. Relevant clinical data was retrieved. In case of a neoplastic diagnosis, second consultation from another Histopathologist in the department was taken. Data was entered and analyzed by using Microsoft excel 2010 and the results were prepared.

\section{Results}

Youngest patient included in study was 16 years old and eldest was 70 years old. Maximum 149 (48 \%) patients were within age range of 11-30 years, while $131(43 \%)$ patients were in age range of $31-50$ years and 27 (9\%) patients were in age range of 51-70 years. Out of 307 cases, $47(15 \%)$ were male patients and $260(85 \%)$ were female patients thus making female to male ratio of 5.5:1 as shown in figure 1 .

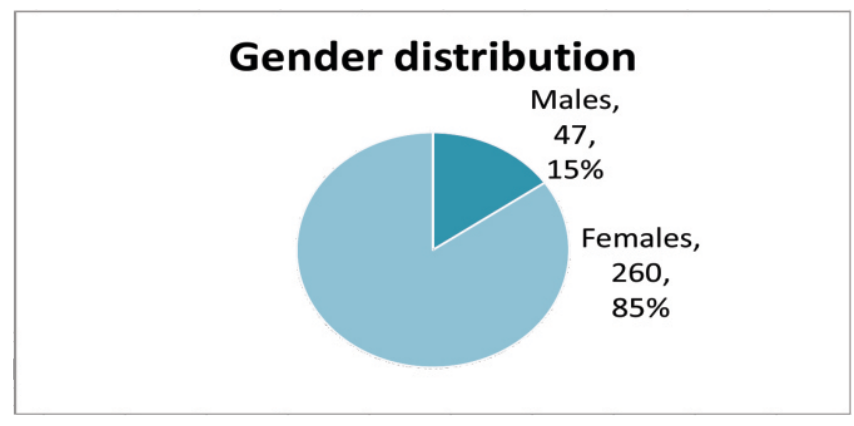

Fig.1: Gender Distribution of Thyroid Diseases

Histopathology revealed non neoplastic lesions in 241(78.5\%) specimens and neoplastic lesions in $66(21.5 \%)$ cases. Amongst non neoplastic entities, majority 229(95\%) cases comprised of colloid goiter and $12(5 \%)$ cases showed histologic evidence of Hashimoto thyroiditis.

Out of these 66 neoplastic lesions, there was equal contribution of benign $33(50 \%)$ and malignant $33(50 \%)$ cases. Diagnosed benign entities were follicular adenoma $29(88 \%)$ cases, Hurthle cell adenoma $3(9 \%)$ cases and there was $1(3 \%)$ rare case of hyalinizing trabecular tumor (Table 1).

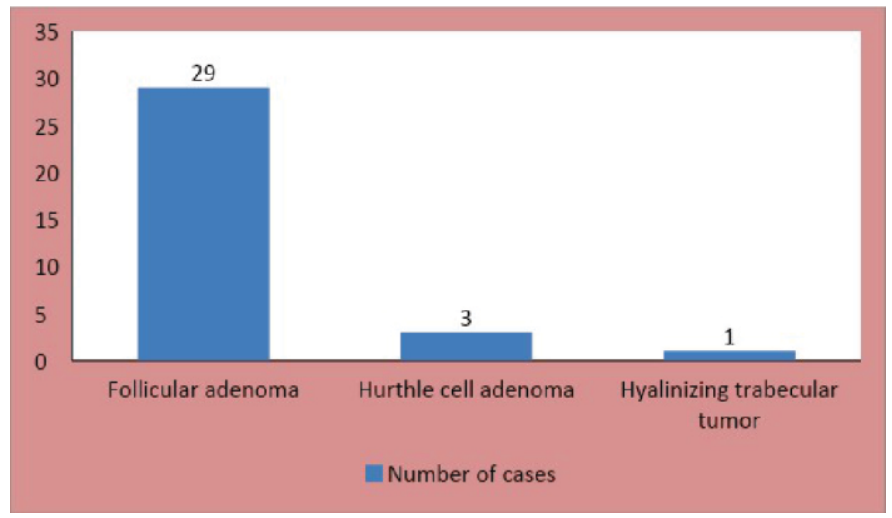

Fig. 1: Benign Neoplastic Thyroid Lesions

Malignant thyroid cases diagnosed during the period were as follows (Table 2); papillary carcinoma $19(58 \%)$, papillary microcarcinoma $4(12 \%)$, follicular carcinoma $3(9 \%)$, medullary carcinoma $3(9 \%)$, anaplastic carcinoma 2(6\%), insular carcinoma $1(3 \%)$, and medullary microcarcinoma $1(3 \%)$.

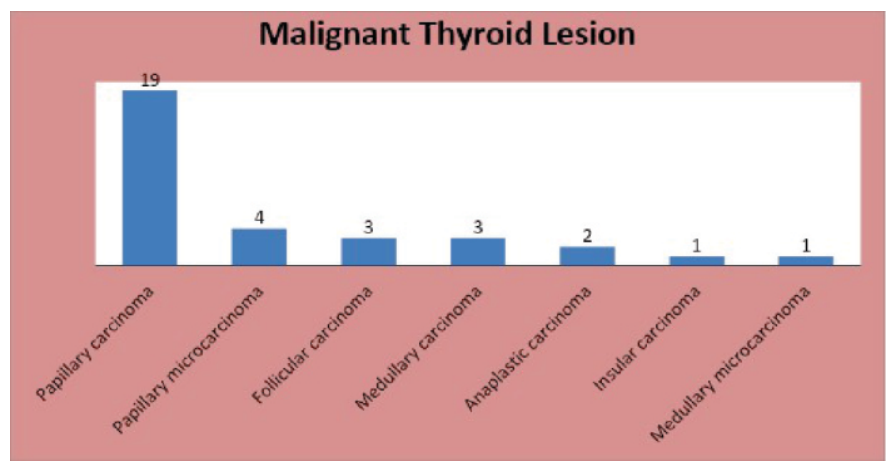

Fig. 2: Malignant ThyroidLesions

Papillary carcinoma was seen in all age groups with maximum number of cases ${ }^{6}$ seen in age group of 1630 years. Follicular and anaplastic carcinoma were seen in age group of 46-60\%. Insular carcinoma was seen in 61-75 years of age while follicular adenoma also showed maximum number in younger population. Table 3 shows correlation of age with various benign and malignant thyroid diseases.

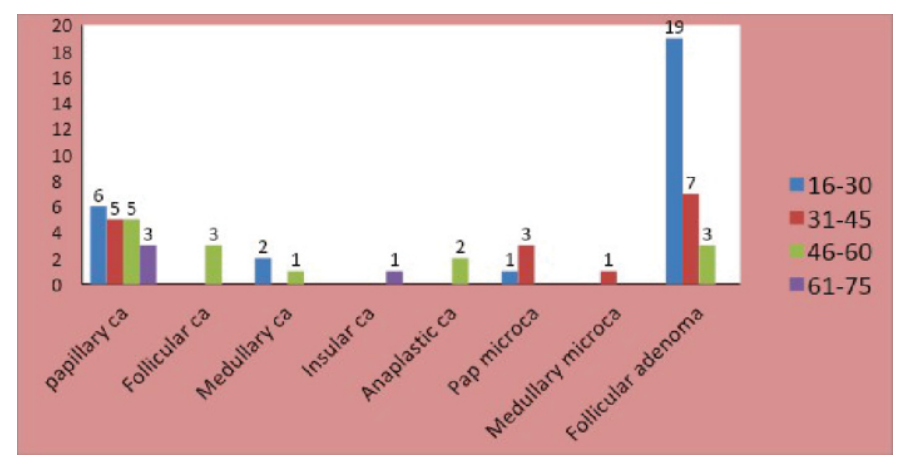

Fig.3: Correlation of Age with Histopathologic Categories 
Rigreustaidy:including 3452 patients. ${ }^{12}$ Follicular and medullary carcinoma contributed as $9 \%$ each in our

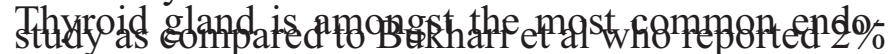
erine glandinfliated barcarioms pathologies. Thyroid

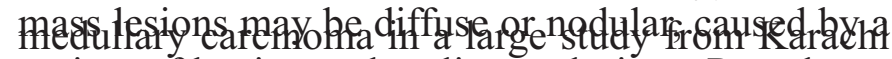

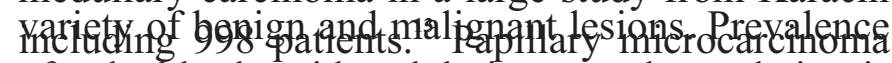

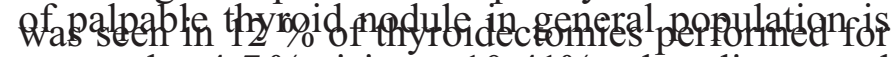

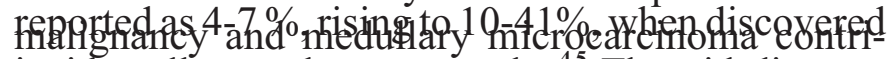

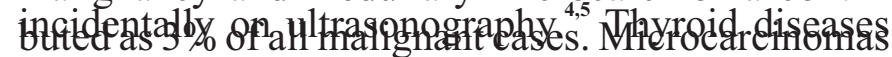

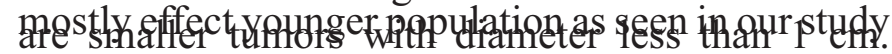

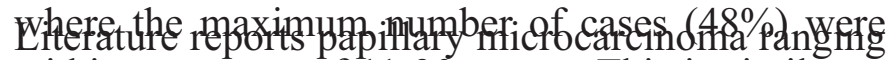

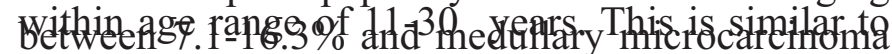
cases deported by Itagi et al in which maximum number of patients with thyroid nodules were seen in Ggorrahgeiof $\$ 1-30$ years. ${ }^{6}$

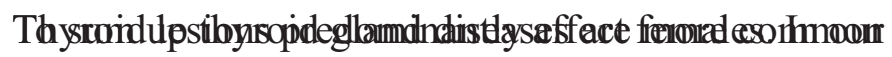

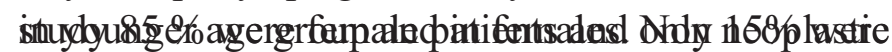

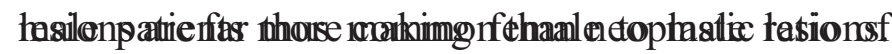

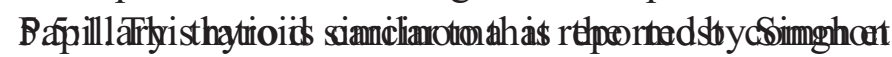

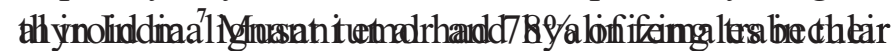
stundgr ishaiter theeraignathstureidguffermale predominance $(89 \%)$ in a study conducted by Fatima et al. ${ }^{3,8}$

\section{Author's Contribution}

AYRs Adt dilitod histopathologic examination, 78.5\% of

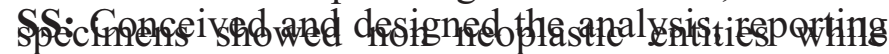
$2 f$ çosenad neoplastic lesions. Sanjeeva et al had more Si:Data Collection data analysis amounting to $91 \%$ TA Deata collection reporting of cases $2015^{9}$.' In our Referendesinodular colloid goiter (Figure 2) was the commonest non eeoplastic enlarged thyroid, entity (95\%) . Hashimpto thyrgielitis

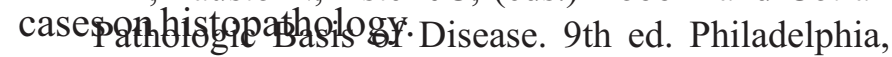

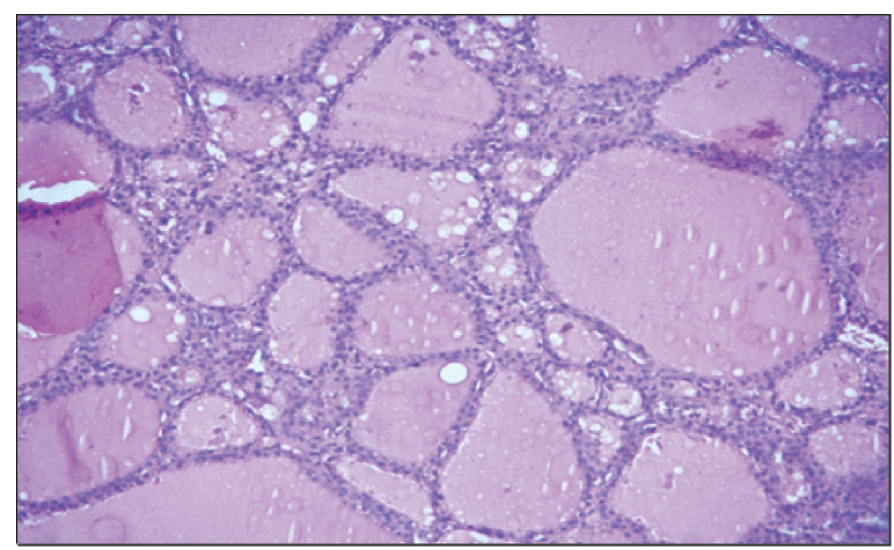

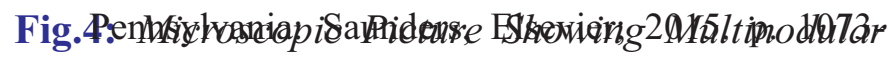
CollditaGoiter with Multiple Colloid Filled Cystic Spaces and Benign Histology

In neoplastic benign entities follicular adenoma was commonest accounting $88 \%$ of cases. This is follo-
Fred Aye

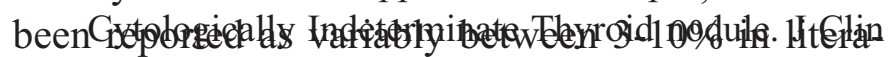

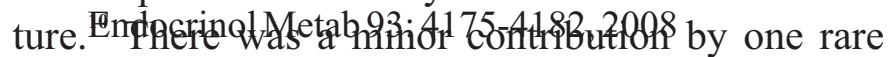

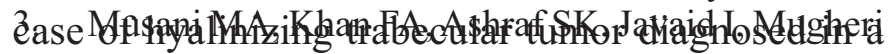
young, 24 aly shows venting at FepTrdepartment. Fyaluation by Fny reng

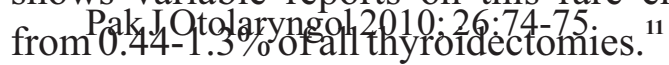

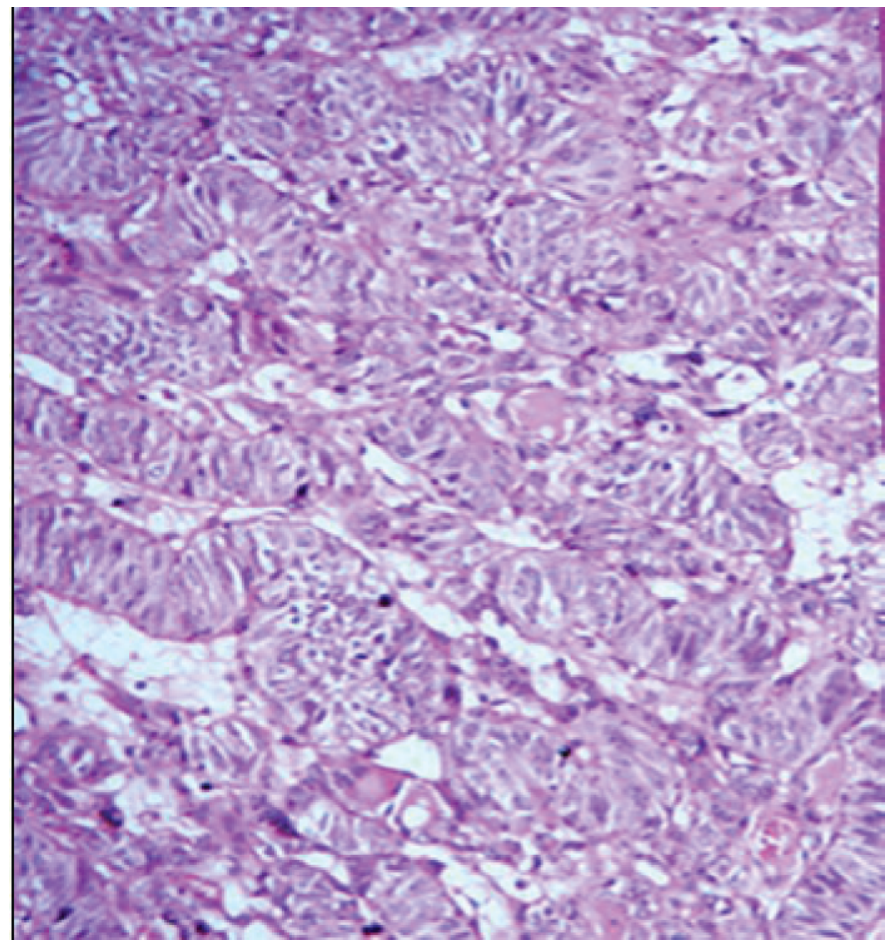

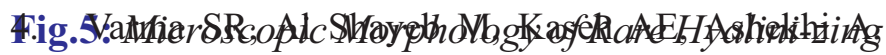

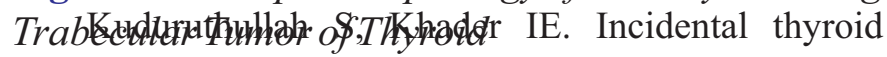
nodules an ultrasound screening of the neck region:

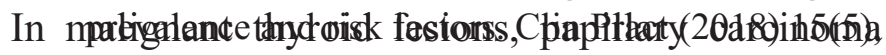
outnühbered other malignancies reaching a toll of

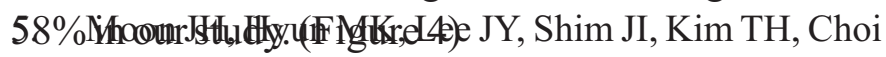

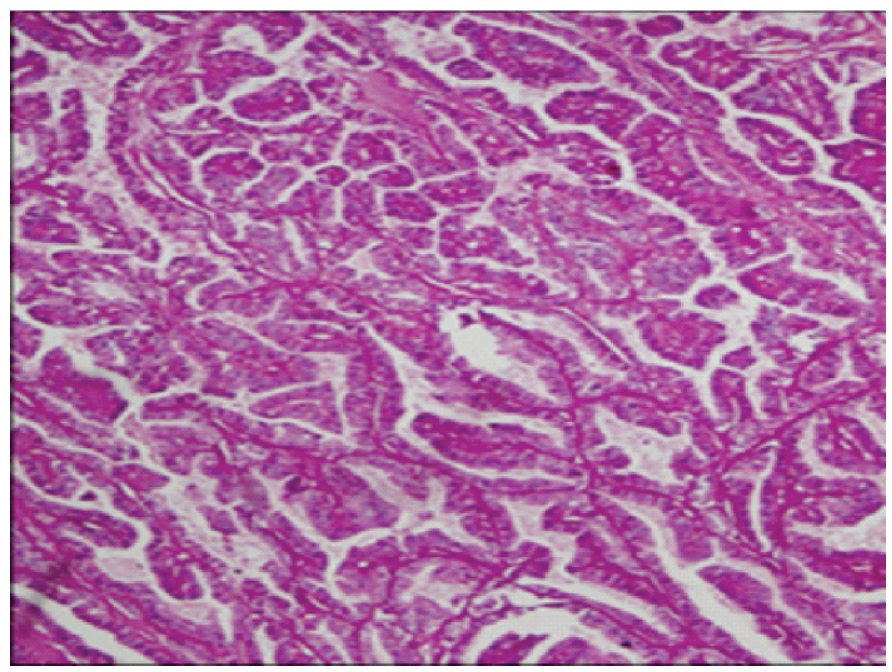

Fig.6: Papillary Thyroid Carcinoma

This is comparable to study by Burgess et al who reported $65 \%$ papillary thyroid carcinoma in their 
large study including 3452 patients. ${ }^{12}$ Follicular and medullary carcinoma contributed as $9 \%$ each in our study as compared to Bukhari et al who reported $2 \%$ cases of follicular carcinoma and $4.5 \%$ cases of medullary carcinoma in a large study from Karachi including 998 patients. ${ }^{13}$ Papillary microcarcinoma was seen in $12 \%$ of thyroidectomies performed for malignancy and medullary microcarcinoma contributed as 3\% of all malignant cases. Microcarcinomas are smaller tumors with diameter less than $1 \mathrm{~cm}$. Literature reports papillary microcarcinoma ranging between $7.1-16.3 \%$ and medullary microcarcinoma around $2 \%{ }^{14,15}$

\section{Conclusions}

To sum up thyroid gland diseases are more common in younger age group and in females. Non neoplastic lesions are far more common than neoplastic lesions. Papillary thyroid carcinoma is the most common thyroid malignant tumor and hyalinizing trabecular tumor is a rare benign thyroid tumor.

\section{Author's Contribution}

INR: Author

SS: Conceived and designed the analysis, reporting of cases

SI: Data Collection, data analysis

TA: Data collection, reporting of cases

\section{References}

1. Maitra A. The Endocrine System. In: Kumar V, Abbas AK, Fausto N, Aster JC, (eds.) Robbin and Cotran Pathologic Basis of Disease. 9th ed. Philadelphia, Pennsylvania: Saunders, Elsevier; 2015. p. 10731140.

2. Alexander EK. Approach to the patient with a Cytologically Indeterminate Thyroid nodule. J Clin Endocrinol Metab 93: 4175-4182, 2008

3. Musani MA, Khan FA, Ashraf SK, Javaid I, Mugheri $\mathrm{N}$, Malik $\mathrm{S}$ et al. Spectrum of thyroid diseases presenting at ENT department. Evaluation by FNAC. Pak J Otolaryngol 2010; 26:74-75

4. Varma SR, Al Shayeb M, Kaseh AE, Ashekhi A, Kuduruthullah S, Khader IE. Incidental thyroid nodules an ultrasound screening of the neck region: prevalence and risk factors. Clin Pract (2018) 15(5), 873-879
5. Moon JH, Hyun MK, Lee JY, Shim JI, Kim TH, Choi HS et al. Prevalence of thyroid nodules and their associated clinical parameters: a large scale, multicenter-based health checkup study. Korean J Intern Med 2018; 33:753-762

6. Itagi IR, Sangavi AB. Assessment of histopathology findings associated with thyroidectomies: A retrospective study. International Journal of Contemporary Medical Research 2017; 4(9): 1872-1875

7. Singh S, Sudhalyengar. Histopathological spectrum of thyroid gland lesions in a tertiary care center- A five year retrospective study. Journal of Medical and Dental sciences. Volume 18, Issue 2, Ser.7(February 2019), PP 70-73

8. Fatima A, Tolnur RA, Patil BV, Dombale VD. Histopathological spectrum of thyroid lesions. Indian Journal of Pathology and Oncology, April-June, 2018; 5(2):298-301

9. Sanjeeva KK, Chandra B, Balakrishna MA, Ramesh DB. Clinico-epidemiological study and treatment outcome of multinodular goiter at a tertiary care hospital. Journal of Clinical and Diagnostic Research. 2015 Jun, Vol-9(6):PC22-PC25

10. Shawky M, Sakr M. Hurthle cell lesion: Controversies, challenges and debates. Indian J Surg (February 2016) 78(1): 41-48

11. Jones DJ, Kieliszak CR, Patel SS, Selinsky CR. Hyalinizing trabecular tumor of the thyroid gland and its significant diagnostic issue. Thyroid Research (2017) 10:7

12. Burgess JR, Tucker P. Incidence trends for papillary thyroid carcinoma and their correlation with thyroid surgery and thyroid fine-needle aspirate cytology. Thyroid. 2006;16(1)

13. Bukhari U, Sadiq S, Memon J, Baig F. Thyroid carcinoma in Pakistan: a retrospective review of 998 cases from an academic referral center. Hematol Oncol stem Celt her 2009: 2(2);345-348

14. Senel F, Karaman H, Aytekin A, Silov G, Bayram A. Incidental papillary thyroid microcarcinomas in thyroidectomy specimens: A single-center experience from Turkey. Indian J Pathol Microbiol 2019; 62:211-5

15. Kaliszewski K, Wojtczak B, Karpinska MS, Lukienczuk T, Forkasiewcz Z, Domoslawski P. Incidental and non-incidental thyroid microcarcinoma. Oncol Let 2016:12;734-740 